\title{
Progresso científico em melhoramento animal no Brasil na primeira década do século XXI
}

\section{Raysildo Barbosa Lôbo ${ }^{1}$, Thereza Cristina Bório dos Santos Calmon de Bittnecourt ${ }^{2}$, Luís Fernando Batista Pinto}

\footnotetext{
${ }_{1}$ Associação Nacional de Criadores e Pesquisadores (ANCP) e Universidade de São Paulo.

2 Universidade Federal da Bahia - Escola de Medicina Veterinária e Zootecnia - Departamento de Produção Animal.
}

RESUMO - O Brasil é um dos lideres mundiais em produção de animais de interesse zootécnico. Porém, para manter este status, precisa investir grandemente em pesquisas que visem aumentar a produtividade animal. No âmbito do melhoramento genético animal, o Brasil conta com muitos grupos que desenvolvem estudos de grande interesse nesta área. São estudos que vão desde os clássicos trabalhos de estimativas de componentes de variância e parâmetros genéticos, passando por trabalhos de modelagem estatística até chegar aos trabalhos mais recentes envolvendo genética molecular aplicada ao melhoramento animal. Assim, a presente revisão tem por objetivo sumarizar os caminhos pelo qual o melhoramento genético animal no Brasil trilhou ao longo da primeira década do século 21, os quais podem indicar os avanços obtidos e os novos desafios.

Palavras-chave: genômica, herdabilidade, monogástricos, QTL, ruminantes

\section{Scientific progress in animal breeding during the first decade of XXI century}

\begin{abstract}
Brazil is an important world leader in animal yield, but to maintain this status, needs to invest heavily in research to increase animal productivity. For Animal Breeding purpose, Brazil has many groups that develop important studies. Those studies ranging from estimating components of variation and genetic parameters, statistical modeling, and molecular markers applied to animal breeding. Thus, this review aims to summarize the research in animal breeding in Brazil through the first decade of the 21st century, which can indicate the progress and new challenges.
\end{abstract}

Key Words: candidate gene, genomics, heritability, monogastric, ruminants

\section{Introdução}

No Brasil há grupos de pesquisadores em melhoramento animal que desenvolvem estudos para aprimoramento dos processos de avaliação genética e seleção, para a análise de cruzamentos, para ajuste de modelos estatísticos e na aplicação da biologia molecular para fins de melhoramento animal. Alguns destes estudos são antigos, portanto, não caracterizam um avanço das pesquisas em melhoramento animal no Brasil ao longo do século XXI e sim uma consolidação dessas pesquisas e da importância do melhoramento genético para a produção animal. O que caracteriza o avanço do melhoramento animal brasileiro, na primeira década do século XXI, é: a busca por novas características de interesse econômico com potencial para se tornarem critério de seleção; o aprimoramento de modelos estatísticos para estimação de componentes de variância; e o amplo campo aberto pelos novos achados da biologia molecular. Assim, o presente texto foi subdividido em enfoque quantitativo-clássico e enfoque quantitativomolecular. No enfoque quantitativo-clássico abordam-se alguns estudos sobre modelagem e a definição de novos fenótipos de interesse em processos de seleção, enquanto no enfoque quantitativo-molecular descreve-se uma breve revisão dos principais resultados de QTL (Quantitative Trait Loci) e polimorfismos em genes que influenciam características de interesse econômico, obtidos em estudos realizados no Brasil.

O enfoque quantitativo clássico

\section{Modelagem}

Muitos estudos no Brasil foram desenvolvidos para tornar as estimativas de componentes de variância mais robustas, principalmente, quando a espécie de interesse é a bovina. Por exemplo, a conexidade entre os rebanhos é de suma importância para obtenção das estimativas de valor genético, fato que ficou claro no início do século XXI, quando Carneiro et al. (2001) relataram que o uso de dados 
com baixa conexidade reduz o valor fenotípico médio, principalmente para características de baixa herdabilidade e tamanho reduzido de progênie. Outro exemplo está relacionado aos muitos programas de avaliação genética de bovinos de corte, os quais utilizam diferentes modelos de ajuste para peso vivo. A obtenção de pesos em diferentes idades é de suma importância para avaliação de desenvolvimento ponderal, entretanto, a padronização dos pesos para uma idade referência torna-se necessário para efeito de comparação. Lôbo \& Martins Filho (2002) analisaram diferentes métodos de padronização dos pesos aos 205, 365 e 550 dias de idade e constataram diferenças entre as médias dos pesos corporais calculadas pelos diferentes métodos, bem como diferenças nas estimativas de componentes de variância e de parâmetros genéticos. Assim, o método de padronização de peso pode influenciar o processo de seleção.

A heterogeneidade de variância também foi enfoque em estudos de simulação. Carvalheiro et al. (2002), ao realizarem um estudo de simulação, concluíram que os efeitos da heterogeneidade de variância residual sobre as avaliações genéticas estão associados à pressão de seleção e aos níveis de heterogeneidade. Quando as devidas correções não são efetuadas, rebanhos que praticam seleção intensa e apresentam níveis acentuados de heterogeneidade de variância residual podem ter seus animais classificados de maneira incorreta e, conseqüentemente, menor resposta à seleção. Segundo Toral et al. (2009), a divisão em 20 classes heterogêneas para peso em diferentes idades na raça Canchim foi o modelo de melhor ajuste. Entretanto, estes autores citam que é possível agrupar classes com variâncias residuais semelhantes para reduzir o número de parâmetros estimados e a demanda computacional.

A eficácia dos modelos mistos foi objetivo de estudo de Mercadante et al. (2003), os quais concluíram que a incorporação de todas as informações disponíveis em modelo misto para estimar a mudança genética ao longo dos anos fornece uma curva mais suavizada das médias anuais e estima a tendência genética anual com menor erro-padrão. Comparação de métodos foi enfoque de estudo de Carneiro Jr. et al. (2004), os quais relatam que o método REML (Máxima Verossimilhança Restrita) com modelo animal pode ser considerado mais apropriado para estimar componentes de variância para características de baixa herdabilidade, quando comparado ao método da máxima verossimilhança (ML) ou ao método III de Henderson. Azevedo et al. (2002) também recomendaram o método REML para estimação de componentes de variância para dados de interesse econômico em aves quando comparado ao método III de
Henderson. A estatística Bayesiana também norteou alguns estudos para comparação de modelos. Carneiro Jr. et al. (2005) concluíram que a inclusão de informação a priori proporciona melhores resultados para estimação dos componentes de variância, sobretudo em populações pequenas. Comparações da Inferência Bayesiana x Escola Frequentista foram abordados em estudos de Toral et al. (2007), os quais constataram que as covariâncias e os parâmetros genéticos estimados por REML, na maioria dos casos, são inferiores às médias a posteriori obtidas por Inferência Bayesiana. Porém Carneiro Jr. et. al. (2007) recomendam o método Bayesiano para populações de tamanho pequeno e apenas quando há disponibilidade de priors informativas. Por outro lado, Idalmo et al. (2007) demonstraram que o modelo Gaussiano é inadequado para estimar a variância residual nas situações em que há contaminação nos dados, enquanto a Inferência Bayesiana em modelo Robusto, nas situações de heterogeneidade de variância residual, permite identificar esta contaminação e obter melhores resultados na predição do valor genético. Por fim, Cardoso et al. (2009) apresentam a flexibilidade dos modelos hierárquicos bayesianos para ajustar algumas características de desempenho animal, que por sua complexidade não podem ser adequadamente analisadas por meio dos modelos lineares clássicos.

O estudo de medidas repetidas é de suma importância nas avaliações genéticas, pois diversas características de interesse na produção animal são avaliadas repedidas vezes ao longo da vida do animal, o que as caracteriza como dados longitudinais. Freitas et al. (2005) fizeram um detalhado estudo de análise de medida repetidas em bovinos de corte e concluíram que a transformação Box-Cox dos pesos de Nelore, Guzerá, Gir e Indubrasil reduz os coeficientes de assimetria e da heterogeneidade de variância para todas as pesagens e raças. Segundo estes mesmos autores, a estrutura de covariância mais adequada para modelar dados de pesos, do nascimento até dois anos de idade, para todas as raças foi a Não-Estruturada, seguida da estrutura Fator-Analítico para Nelore, Gir e Indubrasil, e da Simetria Composta Heterogênea, para Guzerá. Também avaliando medidas repetidas, Toral et al. (2006) relataram que as melhores estruturas de covariâncias residuais foram a Fator Analítico de Primeira Ordem e a Não Estruturada, que consideram o aumento das variâncias com o aumento da idade do indivíduo e as correlações diferentes para cada par de medidas de peso. Ainda para análise de dados longitudinais, constatase o grande crescimentos dos estudos de análise de regressão aleatória, que povoaram muitos artigos na área de melhoramento animal no Brasil ao longo da primeira década 
do século XXI como pode ser observado em El Faro e Albuquerque (2003), Dias et al. (2007), Tholon \& Queiroz (2009) e Sousa Jr. et al. (2010), pois os modelos de regressão aleatória consideram a estrutura de covariâncias entre as medidas realizadas nas diferentes idades abrangidas pela avaliação e possibilitam a descrição dos componentes envolvidos no controle da característica de interesse.

A inclusão de mais efeitos (fixos ou aleatórios) nos modelos estatísticos também tem sido objetivo de estudo. Cunha et al. (2009) comprovaram por simulação que a variância de dominância real, não-acomodada pelo modelo misto aditivo, é redistribuída entre os componentes genético aditivo e residual, com conseqüente superestimação desses componentes e redução da acurácia das avaliações genéticas. Corrêa et al. (2010) compararam as estimativas dos valores genéticos de reprodutores utilizando modelos animal e hierárquico normas de reação, que considera o efeito da interação genótipo-ambiente, e constataram que é necessário considerar esta interação no processo seletivo a fim de aumentar o ganho genético em cada ambiente específico.

Hoje a meta-análise tem grande atenção nas diversas linhas de pesquisa em produção animal, pois a análise conjunta de um grande número de estudos pode ajudar na obtenção de estimativas mais acuradas de importantes parâmetros estatísticos. Porém, Giannotti et al. (2004) já utilizavam a meta-análise no terço inicial desta década para identificar os fatores que mais afetam as estimativas de herdabilidade, constatando que a raça e o método de estimação são muito importantes. Outros estudos com meta-análise podem e devem ser conduzidos a fim de sumarizar as informações sobre componentes de variância e parâmetros genéticos, devido ao grande número de referências disponíveis com informações destas estimativas no Brasil.

\section{Novos fenótipos de interesse para seleção}

\section{Qualidades de carne e de carcaça}

Qualidades de carne e de carcaça tornaram-se uma demanda para o século XXI, devido ao aumento das exigências do mercado consumidor, principalmente, o externo. A principal raça de bovinos de corte do Brasil, a Nelore, deve se tornar alvo de muitos estudos neste fator, pois Bonilha et al. (2007) observaram que a seleção desta raça apesar de provocar maiores pesos de abate e de carcaça não tem alterado os rendimentos de carcaça e da porção comestível. Além disso, segundo estes autores, animais do grupo Nelore Seleção apresentaram carne menos macia que animais Nelore Controle e Caracu. Alternativas úteis seriam os cruzamentos, pois Vaz et al. (2002), ao estudarem 463 novilhos, das Raças Charolês, Nelore e cruzados F1 destas duas raças, constataram que o cruzamento entre Charolês e Nelore propiciou heterose positiva e complementaridade genética aditiva para características de carcaça e da carne, importantes para frigoríficos e consumidores. Perotto et al. (2009) também avaliaram cruzamentos com Nelore (1/2Guzerá $+1 / 2$ Nelore, $1 / 2$ Red Angus + 1/2Nelore e 1/2Marchigiana + $1 / 2$ Nelore) observando importantes alterações causadas pelo efeito de grupo genético, principalmente para pesos de carcaça quente, do dianteiro, da carne do costilhar e os pesos da carne e dos ossos do dianteiro. A crescente importância do rendimento de cortes nobres e de qualidade da carcaça tem levado ao aumento de avaliações do longissimus dorsi e da espessura de gordura na carcaça, principalmente, por ultrassom. Entretanto, Mercadante et al. (2010) observaram que a experiência do técnico tem grande efeito sobre as avaliações via ultrassom, pois constataram que técnico com maior experiência apresenta maiores valores de repetibilidade para mensurações da área do músculo longissimus dorsi e da espessura de gordura subcutânea. Assim, os autores recomendam que as imagens de animais pertencentes a um mesmo grupo de contemporâneos sejam feitas por um único técnico. Apesar destas considerações, não há dúvidas de que as avaliações de carcaça, por meio de ultrassom, vieram para ficar. Elas propiciam a possibilidade de avaliar in vivo características que podem contribuir para melhoria da qualidade das carcaças. Além disso, uma vez que o processo de obtenção das imagens é relativamente simples, a obtenção das imagens em larga escala pode permitir a inserção destas características em programas de avaliação genética em andamento no Brasil.

Avaliações por escores visuais também estão sendo motivo de estudo em avaliações de bovinos de corte quanto à conformação e musculosidade. Koury Filho et al. (2010) estimaram coeficientes de herdabilidade ao sobreano de 0,24; 0,32 e 0,27 para conformação, precocidade e musculatura, respectivamente. Relatando ainda correlações genéticas variando de moderada a alta magnitude entre o peso corporal a desmama e ao sobreano com conformação, precocidade e musculatura. Estes resultados indicam que os escores visuais podem ser utilizados como critérios de seleção e que o aumento nos pesos corporais deve ser esperado como resposta correlacionada à seleção para essas características.

\section{Precocidade reprodutiva}

Reprodução sempre foi um dos aspectos de maior impacto na lucratividade dos sistemas de produção animal. Assim, muitos estudos têm buscado avaliar a precocidade 
reprodutiva, principalmente de bovinos dado o elevado intervalo de geração desta espécie. Uma das mais importantes características para avaliar precocidade reprodutiva em fêmeas é a idade ao primeiro parto (IPP), porém, trata-se de uma característica que, geralmente, apresenta baixa herdabilidade. Boligon et al. (2008) estimaram coeficientes de herdabilidade de IPP em 0,14, o que indica que a seleção direta para IPP na raça Nelore pode não ter a resposta esperada. Baldi et al. (2008a) também estimaram baixos coeficientes de herdabilidade para idade ao primeiro, segundo e terceiro partos em 0,10; 0,08 e 0,14, respectivamente, na raça Canchin. Porém, alguns estudos evidenciaram herdabilidades moderadas para IPP, como Azevedo et al. (2006a, b), que estimaram os valores de 0,36 e 0,21, para as raças Chianina e Nelore, respectivamente. Devido à baixa herdabilidade de IPP, precocidade reprodutiva de matrizes bovinas também vem sendo avaliada por idade de confirmação da primeira prenhez, pois aparentemente trata-se de uma característica com maior herdabilidade que IPP. Silva et al. (2003) estimaram coeficiente de herdabilidade para probabilidade de prenhez aos 14 meses de idade igual a 0,73 , na raça Nelore. Silva et al. (2005) observaram elevada herdabilidade $(0,52)$ para prenhez aos 16 meses na raça Nelore. Shiotsuki et al. (2009) estimaram o coeficiente de herdabilidade direta para Prenhez aos 16 meses em 0,50 , o que indica que essa característica pode ser utilizada como critério de seleção na raça Nelore. Alguns estudos mostram que a seleção para aumento de peso pode estar aumentando a precocidade de matrizes bovinas. Boligon et al. (2010) constataram que a seleção para maior ganho de peso pode reduzir a idade ao primeiro parto e aumentar o peso adulto de fêmeas da raça Nelore. Porém, Shiotsuki et al. (2009) também constataram que a seleção para animais mais pesados a desmama pode diminuir a ocorrência de prenhez aos 16 meses.

Precocidade reprodutiva de machos bovinos também é objetivo de estudo e neste caso, perímetro escrotal tem sido a medida mais utilizada para este fim. Dias et al. (2003) avaliaram precocidade em machos da raça Nelore por meio da análise de perímetro escrotal e encontraram estimativas de herdabilidade variando de 0,35 a 0,42 , em função do modelo ajustado. Mattar et al. (2007) estimaram coeficiente de herdabilidade para perímetro escrotal ao sobreano na raça Caracu de 0,38, o que permite utilizá-lo como critério de seleção para precocidade sexual. Além disso, perímetro escrotal pode ser uma característica que evidencia precocidade em nas filhas de touros com elevado perímetro escrotal. Boligon et al. (2007) observaram que a seleção para maior perímetro escrotal aos 18 meses de idade pode resultar, a longo prazo, em menor idade ao primeiro parto na raça Nelore. Pereira et al. (2007b) observaram resultado semelhante na raça Canchin, pois estimaram a correlação genética de -0,37 entre idade ao primeiro parto e perímetro escrotal.

\section{Habilidade de permanência no rebanho}

Segundo Baldi et al. (2008b) a seleção para redução na idade ao primeiro parto não incrementará a produtividade das vacas e aumentar o peso adulto das fêmeas pode reduzir o quilograma de bezerro desmamado por ano de permanência da matriz no rebanho, além do número de bezerros desmamado por matriz durante seu tempo de permanência no rebanho. Assim, a habilidade de permanência das matrizes no rebanho é outra característica que vem sendo alvo de estudo em bovinos. Queiroz et al. (2007) avaliaram a raça Caracu e obtiveram estimativas moderadas de herdabilidade para permanência no rebanho até 48 meses de idade $(0,28)$, para permanência no rebanho até 60 meses de idade $(0,27)$ e para permanência no rebanho até 72 meses de idade $(0,23)$, o que viabiliza sua utilização como critério de seleção. Outro enfoque para avaliar produtividade de matrizes bovinas de corte é mensurar a "produtividade acumulada”, que é um índice para precocidade sexual, periodicidade reprodutiva e potencial de produção de quilogramas de bezerros por matriz. Entretanto, Azevedo et al. (2005) encontraram baixa herdabilidade $(0,11)$ para produtividade acumulada na raça Nelore.

\section{Pelame}

Em bovinos de leite, muitas perdas são causadas por reduzida adaptação as condições de clima tropical, principalmente na raça Holandesa, cujos primeiros trabalhos de seleção foram conduzidos em clima temperado e ainda hoje o Brasil importa material genético desta raça. Assim, a busca de características alternativas que proporcionem maior conforto térmico pode ser de grande valia neste sistema de produção. Maia et al. (2003) constaram que a seleção de vacas predominantemente negras pode ser uma boa escolha para aumentar a resistência do gado Holandês à radiação solar, devido a epiderme sob esse tipo de malha ser altamente pigmentada. Tal seleção pode ser facilmente realizada, considerando a alta herdabilidade $(0,75)$ para a proporção de malhas negras, segundo Maia et al. (2003). Outro problema do sistema de produção nos trópicos é a alta incidência de ecto e endo-parasitos. Assim, Fraga et al. (2003) avaliaram a resistência a carrapatos (Boophilus microplus) na raça Caracu e constataram que, quanto maior a espessura do pelame, maior o nível de infestação. O coeficiente de herdabilidade para número de carrapatos foi 
0,22, o que sugere ser possível obter progresso genético para resistência a carrapato via seleção.

\section{Bem-estar}

Bem-estar animal é um fator de suma importância atualmente, o que tem levado as pesquisas no âmbito da produção animal a buscarem alternativas a fim de reduzir o estresse em pontos críticos da atividade pecuária. Em bovinos de corte um dos momentos de maior estresse é a pesagem em idades chaves como a desmama e ao sobreano. Maffei (2008) propõe a mensuração da reatividade animal no momento da pesagem como uma medida que vise à obtenção de animais mais tolerantes ao manejo diário nas propriedades. Segundo este autor, trata-se de uma característica objetiva e de fácil mensuração, cuja herdabilidade na raça Nelore é de 0,39 para pesagem ao ano e 0,23 ao sobreano. Relata ainda que as correlações desta medida com ganho de peso do desmame aos 12 meses $(-0,49)$ e com desenvolvimento do perímetro escrotal do ano ao sobreano (entre -0,25 e -0,41), evidenciam que os animais mais reativos tendem apresentar menor desenvolvimento no período pós-desmama.

Aves e Suínos

Ao longo do século XXI foram poucos os trabalhos de análise quantitativa para fins de melhoramento de Suínos e Aves no Brasil, principalmente, se comparado ao volume de trabalhos com bovinos. Características tradicionalmente utilizadas na avaliação de aves foram abordas no estudo de Vayego et al. (2008). Estes autores avaliaram peso corporal e medidas morfométricas de peito aos 42 dias de idade e obtiveram estimativas de herdabilidade variando de 0,29 a 0,53 . Confirmando o potencial destas características para seleção, o que consequentemente resultou no progresso genético entre os anos de 1992 e 2003 na população da Embrapa por eles estudada. Características menos comuns foram avaliadas por Bongalhardo et al. (2000), os quais sugerem com vistas ao aumento da produção total de ovos e do peso do ovo, que seja utilizada a concentração de espermatozóides na $24^{\mathrm{a}}$ e $28^{\mathrm{a}}$ semanas de idade, respectivamente. Enquanto, Gaya et al. (2009) avaliaram medidas de escore visual de fígado e coração de 6167 aves e obtiveram baixos coeficientes de herdabilidade $(0,05)$ para ambas, o que indica reduzido potencial destas medidas para programas de seleção fundamentados apenas no fenótipo do próprio animal.

Quanto aos suínos, as características que predominaram nos estudos ao longo da primeira década do século XXI foram aquelas já tradicionalmente avaliadas em estudos anteriores (peso em idades referência, como aos 100 dias, ganho de peso diário, espessura de toucinho, idade e número de dias para atingir determinado peso, número de leitões e peso da leitegada ao nascimento, número de leitões e peso da leitegada no desmame, número de natimortos e idade da fêmea no primeiro parto), como pode ser observado nos estudos de Pita \& Albuquerque (2001), Torres Filho et al. (2005), Lourenço et al. (2008) e Barbosa et al. (2008). Porém, Costa et al. (2001) já citavam no início deste século a necessidade de ampliar os trabalhos de melhoramento para aumentar o progresso genético de algumas características de interesse econômico em suínos, pois encontraram tendências genéticas indesejáveis ou estagnadas em alguns casos, recomendação semelhante a de Lourenço et al. (2008) já no fim da primeira década deste século. Assim, um desafio para os grupos de pesquisa no Brasil será aumentar o número de pesquisas com aves e suínos, algo que já vem ocorrendo quando se leva em consideração estudos na área de marcadores moleculares, como será visto no decorrer deste texto.

\section{Valor econômico}

A introdução de novos fenótipos em avaliação genética depende logicamente da importância econômica da característica. Porém, estas avaliações econômicas ainda são raras em trabalhos de melhoramento animal, talvez pelo fato de a qualidade dos produtos de origem animal ainda não ser tão bonificada quanto à quantidade destes produtos. A expectativa é que essa realidade mude no curto ou médio prazo, devido ao continuo aumento das exigências dos consumidores. Assim, alguns estudos foram conduzidos para avaliação econômica, principalmente em bovinos de leite. Martins et al. (2003), Cardoso et al. (2004) e Bueno et al. (2004) verificaram que os valores econômicos para os componentes do leite são negativos se a remuneração não bonificar tais componentes. Seno et al. (2007) também encontraram valores econômicos negativos para as produções de gordura e proteína quando o objetivo era apenas a venda do leite de Búfalas. Porém, quando o objetivo era a comercialização de mozarela, os valores econômicos foram de R \$3,05, R \$18,66 e R \$54,38, para leite, gordura e proteína, respectivamente. Segundo Ribeiro et al. (2009), uma boa medida de rentabilidade é a receita do leite menos o custo de alimentação, que poderia ser utilizada como critério de seleção para Receita Liquida Vitalícia, pois é uma informação de fácil obtenção.

Jorge Jr. et al. (2007) realizaram análise econômica de algumas características de interesse em bovinos de corte e constataram que a taxa de desmama tem grande impacto sobre a rentabilidade, tanto no sistema de produção de ciclo de cria quanto no de ciclo completo, enquanto o rendimento de carcaça foi de grande importância econômica em rebanhos 
de ciclo completo. Evidenciando assim a importância dos recentes estudos em aumento da eficiência reprodutiva e da melhoria da carcaça em bovinos de corte. Segundo estes autores, a característica consumo alimentar, tanto no confinamento quanto na pastagem, também representa um relevante impacto econômico e deveria ser considerada em objetivos de seleção para gado de corte. Porém, trata-se de uma característica de difícil avaliação em larga escala que talvez seja melhorar avaliada por métodos alternativos, como a utilização de marcadores moleculares.

\section{$O$ enfoque quantitativo-molecular}

Os avanços da biologia molecular trouxeram consigo um novo e amplo campo de pesquisas direcionadas ao melhoramento animal e conservação de recursos genéticos. No Brasil, projetos no âmbito da genômica animal iniciaram na década de 90 do século 20 e se consolidaram como referências a partir da primeira década do século 21 . O sucesso destes projetos revela-se na participação de pesquisadores brasileiros em importantes projetos mundiais como o The Bovine Hapmap Consortium, ver Gibbs et al. (2009) e na elaboração da Rede Genômica Animal, descrita em (http://www.macroprograma1.cnptia.embrapa.br/ GenomicaAnimal), que envolve pesquisadores da EMBRAPA e de diversas universidades brasileiras. A seguir são apresentados alguns resultados obtidos em projetos desenvolvidos no Brasil, no âmbito da genômica aplicada à produção animal e conservação de recursos genéticos, subdividindo em função das diferentes espécies.

\section{Bovinos de leite}

Formar uma população F2 para estudos com bovinos é consideravelmente mais complicado e oneroso que construir uma população semelhante em aves ou suínos, devido ao elevado intervalo de geração da espécie bovina e do custo elevado de manutenção dos animais desta espécie. Entretanto, o Brasil é um dos poucos países a ter uma população F2 desenvolvida para fins de análise genômica. O Centro Nacional de Pesquisa em Gado de Leite (CNPGL) desenvolveu uma população F2, oriunda de cruzamentos entre Holandês x Gir, para fins de análise genômica. Parcerias com centros de pesquisa como a Universidade Federal de Viçosa, a Universidade Federal de Minas Gerais, a Universidade de São Paulo e a Embrapa Pecuária Sudeste, dentre outros, foram estabelecidas para viabilizar o grande aporte de análises estatísticas e laboratoriais deste projeto. Assim, várias características de interesse econômico em bovinos foram avaliadas e alguns resultados foram recentemente publicados (Tabela 1). Para resistência a carrapatos destacam-se os QTLs mapeados por Machado et al. (2010) e Gasparin et al. (2007), enquanto Martinez et al. (2006) associaram polimorfismos no gene BoLA (bovine lymphocyte antigen) com resistência a carrapatos. Por se tratar de um problema tipicamente tropical, existem poucos resultados na literatura sobre QTLs para resistência a carrapatos, o que torna o Brasil uma referência nessa linha de pesquisa. Apesar de peso não ser a principal característica de interesse econômico em bovinos de leite, QTLs associados a desenvolvimento ponderal também foram relatados na população F2 desenvolvida na Embrapa Gado de Leite, por Myata et al. (2007) e Gasparin et al. (2005), como pode ser observado na Tabela 1. Agora, o próximo passo será identificar que genes estão por trás dos efeitos apresentados pelos QTLs mapeados.

Estudos com bovinos de leite no Brasil para identificação de polimorfismos em genes candidatos também são relatados por Silva et al. (2006) para o fator de transcrição da pituitária (PIT-1), para o gene do hormônio do crescimento bovino (bGH) e para o gene IGF-1 (Insulin-like growth factor 1), nos quais descreve associações com pesos e ganhos de peso em diferentes idades (Tabela 1). Enquanto, Nascimento et al. (2006) e Machado et al. (2005) relatam haver associação entre o gene BoLA com produções de proteína e gordura, contagem de células somáticas e produção de leite em 305 dias de lactação, na raça Gir. Azevedo et al. (2008) identificaram polimorfismos no gene da K-Caseína nas raças Sindi, Nelore, Guzerá, Gir e cruzados

Tabela 1 - Revisão dos achados de QTLs e polimorfismos em bovinos de leite no Brasil

\begin{tabular}{|c|c|c|}
\hline Característica & Achado e Local & Referência \\
\hline Resistência a carrapatos & QTL nos cromossomos 2, 5, 10, 11, 23 e 27 & Machado et al. (2010) \\
\hline Resistência a carrapatos & QTL nos cromossomos 5, 7 e 14 & Gasparin et al. (2007) \\
\hline Resistência a carrapatos & Polimorfismo gene Bola & Martinez et al (2006) \\
\hline Pesos ao nascimento e 60 dias de idade & QTL nos cromossomo 14 & Myata et al. (2007) \\
\hline Peso ao nascimento & QTL nos cromossomo 5 & Gasparin et al. (2005) \\
\hline Pesos aos 60, 205 e 365 dias de idade & Polimorfismo gene da pituritária & Silva et al. (2006) \\
\hline $\begin{array}{l}\text { Peso aos } 365 \text { dias de idade e } \\
\text { ganho de peso do nascimento } \\
\text { aos } 60 \text { dias de idade }\end{array}$ & Polimorfismo gene do hormônio do crescimento & Silva et al. (2006) \\
\hline Peso ao nascimento & Polimorfismo gene IGF-I & Silva et al. (2006) \\
\hline
\end{tabular}


Gir x Holandês, com baixa freqüência do alelo favorável, o que indica grande potencial para seleção assistida. Alguns polimorfismos ainda não foram associados com característica de interesse econômico, o que deixa margens a novas pesquisas. Por exemplo, Lacorte et al. (2006) identificaram polimorfismos no gene DGAT1 nas raças Gir, Red Sindi, Holandês e Cruzados F1 Holandês x Gir. Enquanto, Abatepaulo et al. (2008) relatam polimorfismos em genes de resposta imune que podem ser utilizados em estudos que visam ampliar a resistência de bovinos a carrapatos.

\section{Bovinos de corte}

Com bovinos de corte o ponto de partida para estudos de genômica foi a identificação de polimorfismos em genes de interesse e não o mapeamento de QTL. Entretanto, são muitos os estudos de genes candidatos e de identificação de marcadores para seleção assistida em bovinos de corte no Brasil. Talvez uma conseqüência da importância econômica deste segmento na pecuária brasileira, tanto no cenário nacional quanto no internacional. Uma importante parceria foi desenvolvida entre a Merial S/A e o grupo de melhoramento animal e biotecnologia (GMAB) da Faculdade de Zootecnia e Engenharia de Alimentos da Universidade de São Paulo, em Pirassununga-SP. A finalidade deste acordo é estudar genes candidatos para obtenção de marcadores moleculares a serem empregados na seleção de bovinos de corte, principalmente, da raça Nelore. Inúmeras características de interesse econômico foram avaliadas e os primeiros resultados estão sendo publicados. Ferraz et al. (2009) identificaram associação entre SNPs sobre os genes da Leptina e UCP1 (Uncoupling Protein 1) com rendimento de carcaça quente, área do músculo longissimus dorsi e espessura de gordura na carcaça. Essa parceria tem contribuído também para a validação de marcadores moleculares, já comercializados pela Merial S/A para bovinos de origem Bos taurus taurus, em raças de origem Bos taurus indicus como o Nelore. Sem essa validação, muitos dos marcadores poderiam ser equivocadamente utilizados na seleção das raças nacionais, o que poderia resultar em perdas econômicas significativas.

Além da parceira acima descrita, outros trabalhos importantes no Brasil merecem destaque. Millazzotto et al. (2007) relatam associações entre polimorfismos nos genes do receptor do FSH (Follicle Stimulating Hormone) com puberdade em fêmeas da raça Nelore. Porém, Marson et al. (2008) não encontraram o mesmo efeito quando analisaram um composto (Bos taurus taurus x Bos taurus indicus) formado com a contribuição de seis raças. Unanian et al. (2000) relatam associação entre polimorfismos no GH e ganho de peso da desmama até 15 meses de idade na raça
Nelore. Enquanto Tambasco et al. (2002) identificaram associação entre polimorfismos no gene GH e ganho de peso da desmama ao sobreano, em progênies oriundas de matrizes Nelore com touros das raças Aberdeen Angus, Canchim e Simmental.

Estudos com a raça Canchim (5/8 Charolais x 3/8 Zebu) estão sendo desenvolvidos na Embrapa Pecuária Sudeste, local onde esta raça vem sendo selecionada desde meados do século 20. A origem genotípica do DNA mitocondrial (mtDNA) do Canchim era até pouco tempo completamente desconhecida. Entretanto, graças aos avanços da biologia molecular, Méo et al. (2009) demonstraram que um pequeno percentual das progênies avaliadas tinham mtDNA de origem Bos taurus indicus, e atribuíram a grande proporção de mtDNA de origem Bos taurus taurus ao fato de as fêmeas InduBrasil, Guzerá e Nelore, utilizadas na formação da raça, serem na verdade oriundas de cruzamentos entre touros Zebu com fêmeas Bos taurus taurus. Estudos para identificação de polimorfismos na raça Canchim também foram recentemente publicados: Carrijo et al. (2008) observaram efeito de um polimorfismo no gene PIT1 sobre peso ajustado para 240 dias de idade e sobre ganho de peso do nascimento a desmama; Silveira et al. (2008) encontraram associação entre polimorfismo no gene do hormônio do crescimento (GH) e estimativa de valor genético para peso a desmama; Andrade et al. (2008) observaram associação entre polimorfismos no IGF1 e pesos ao nascimento, a desmama e aos 240 dias de idade; enquanto Pereira et al. (2005) identificaram efeito de um polimorfismo no gene $\mathrm{GH}$ sobre peso e polimorfismo sobre o gene IGF1 (Insulin Like Growth Factor 1) associado com os pesos em diferentes idades.

Por fim, para estudo de diversidade gênica destacamse os achados de Machado et al. (2003), que estudaram as raças Holandês, Gir, Guzerá e Nelore. Esses autores observaram que a menor distância genética foi estabelecida entre as raças Nelore e Guzerá e, como esperado, a raça Holandesa apresentou maior distância genética das raças zebuínas. Egito et al. (2007) constaram que uma quantidade significativa de diversidade genética permanece disponível nas raças naturalizadas brasileiras e concluíram que a raça Crioula é uma importante fonte de reserva para melhoramento e conservação de bovinos no Brasil.

\section{Ovinos e Caprinos}

Para caprinos e ovinos são raros os estudos para identificação de polimorfismos ou QTLs que influenciam características de interesse econômico, no Brasil. Porém, a crescente demanda por carne ovina e caprina aliada a importância destas espécies em regiões como o Nordeste 
brasileiro, tenderão a modificar esse panorama em breve. Atualmente, a maioria dos estudos tem sido direcionada à conservação dos recursos genéticos. Petroli et al. (2009), ao estudarem a diversidade genética de um núcleo de conservação da raça Santa Inês, constataram elevado polimorfismo na região do Ovar-MHC (Complexo Maior de Histocompatibilidade ovino), que pode ser usado para auxiliar na manutenção da diversidade de rebanhos desta raça. Oliveira et al. (2005) ao avaliarem diversidade genética de cabras da raça Moxotó demonstraram que a maior parte da variabilidade genética total $(71,55 \%)$ decorre de divergência intra-populacional, enquanto 21,21\% é interpopulacional. Paiva et al. (2005a), ao avaliarem ovinos das raças Santa Inês, Bergamácia, Rabo Largo, Morada Nova e Somalis, com marcadores RAPD, demonstraram que diferenças inter-raciais são responsáveis por 14,92\% da variação total observada; a raça Santa Inês ficou próxima à Bergamácia, enquanto a raça Rabo Largo apresentou maior similaridade com o Santa Inês do que com as raças Morada Nova e Somalis. Em outro estudo, Paiva et al. (2005b) relataram que as raças de ovinos naturalizadas (Santa Inês, Crioula Lanada, Rabo Largo, Morada Nova, Somalis e Bergamácia) podem ser consideradas de origem européia, quando se avalia um fragmento do gene COI (Cytochrome oxidase I). No único artigo encontrado com estudo de associação em ovinos, Lôbo et al. (2009) relatam associações entre o gene Aromatase com: idade ao primeiro parto em animais $1 \frac{2}{2}$ Dorper; intervalo entre partos na raça Santa Inês; e maior peso a desmama no $1 / 2$ Dorper e no Santa Inês. Portanto, mais estudos devem ser conduzidos para avaliar o efeito de importantes genes candidatos sobre características de difícil avaliação, como qualidade de carne e de carcaça, conversão alimentar, consumo de alimentos etc.

Gallus gallus

O projeto brasileiro de genômica de aves teve início em 1999 com a formação da população F2, sendo um esforço conjunto da EMBRAPA Suínos e Aves em Concórdia -SC e da ESALQ/USP em Piracicaba - SP. Uma população F2 foi obtida de um cruzamento inicial entre uma linhagem de corte (TT) selecionada durante seis gerações para melhorar peso corporal, conversão alimentar, consumo de ração, rendimento de carcaça e de partes, viabilidade, fertilidade, eclodibilidade, além de reduzir a gordura abdominal e a ocorrência de doenças metabólicas; e uma linhagem de postura (CC) selecionada durante oito gerações para produção de ovos, peso do ovo, conversão alimentar, viabilidade, maturidade sexual, fertilidade, eclodibilidade e qualidade do ovo. Este projeto é uma importante contribuição brasileira, para desvendar a complexa rede de controle genético dos caracteres de interesse econômico em aves, como pode ser visto em Jorge et al. (2007). Os primeiros estudos na população F2 brasileira de Gallus gallus, foram para identificação de QTLs (Tabela 2) e alguns resultados, recentemente publicados, revelam o sucesso deste projeto, o qual tem colocado o Brasil no patamar dos países que desenvolvem importantes pesquisas para o melhoramento genético de aves.

Assim, com enfoque em peso vivo e pesos de órgãos QTLs são relatados nos estudos de Campos et al. (2009a) nos cromossomos 7 e 8; Ambo et al. (2009) nos cromossomos 2, 3, 4 e 10; e Nones et al. (2006) no cromossomo 1. Neste último estudo foram identificados QTLs para peso de órgãos (Tabela 3) inéditos na literatura até então. Por fim, foram encontrados QTLs nos cromossomos 3, 5, 12, 23 e 27 por Campos et al. (2009b), os quais influenciam importantes características associadas a qualidade de carne (Tabela 3). É necessário ressaltar que muitos dos QTLs encontrados no projeto brasileiro para análise genômica de aves, foram confirmados por populações F2 desenvolvidas em outros países, o que evidencia a qualidade da população brasileira para identificação de QTLs. Isto tem se refletido na aceitação destes artigos em periódicos internacionais considerados de grande fator de impacto nas áreas de Genética e Zootecnia.

Tabela 2 - Revisão dos achados de QTLs e polimorfismos em Gallus gallus no Brasil

\begin{tabular}{|c|c|c|}
\hline Característica & Achado e Local & Referência \\
\hline Peso aos 42 dias de idade & QTLs nos cromossomos 7 e 8 & Campos et al. (2009a) \\
\hline $\begin{array}{l}\text { Peso vivo aos } 35 \text { dias de idade, para peso } \\
\text { aos } 41 \text { dias de idade e comprimento do intestino }\end{array}$ & QTLs nos cromossomos 2, 3, 4 e 10 & Ambo et al. (2009) \\
\hline $\begin{array}{l}\text { Peso vivo em diferentes idades, consumo de } \\
\text { alimento, peso da carcaça, peso da coxa+sobrecoxa, } \\
\text { peso da gordura abdominal, para pesos da moela, } \\
\text { do fígado, dos pulmões, do coração e dos pés, } \\
\text { além de comprimento do intestino }\end{array}$ & QTLs no cromossomo 1 & Nones et al. (2006) \\
\hline $\begin{array}{l}\text { Nível de triglicerídeos, gordura abdominal } \\
\text { e percentual de gordura abdominal }\end{array}$ & QTLs Cromossomos 3, 5, 12, 23 e 27 & Campos et al. (2009b) \\
\hline
\end{tabular}




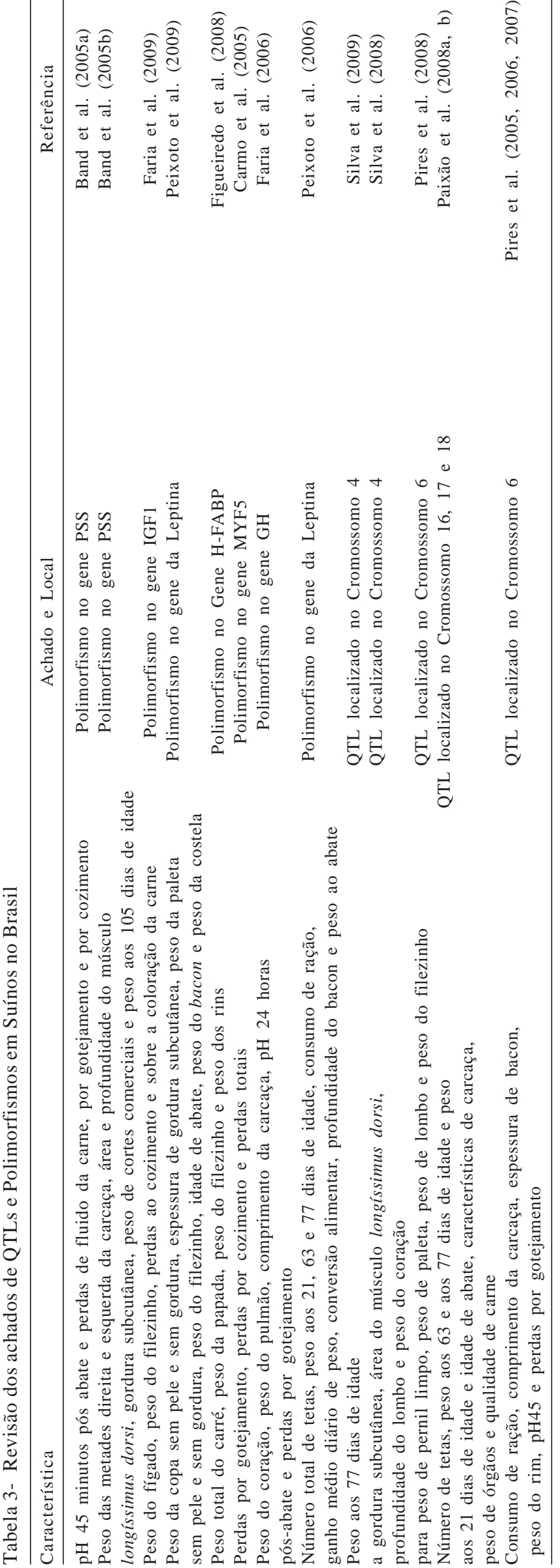

Em outra linha de estudos, porém no mesmo projeto, Cassoli et al. (2007) obtiveram uma coleção de ESTs (Express Sequence Tags) que permitiu identificar genes expressos na pituritária e no hipotálamo, o que pode ser considerado um importante passo para a realização de inúmeros estudos voltados para o aprofundamento do conhecimento sobre o controle fisiológico do desenvolvimento ponderal de frangos. Além disso, identificaram SNPs (Single Nucleotide Polymorphisms) que podem ser potencialmente utilizados como marcadores para avaliação da variação de características de interesse econômico em Gallus gallus. Suínos

A genômica aplicada aos suínos no Brasil caracterizase pela construção de uma população F2 oriunda do cruzamento inicial entre linhagens comerciais e a raça Piau. Segundo Band et al. (2005a), esta $\mathrm{F}_{2}$ foi produzida após cruzamento de fêmeas comerciais (Landrace x Large White e Landrace $\mathrm{x}$ Large White x Pietrain) com reprodutores da raça Piau e criada na Universidade Federal de Viçosa. Resultados de polimorfimos e seus efeitos são citados em Band et al. (2005a) e Band et al. (2005b) para o gene PSS (Porcine Stress Syndrome); Faria et al. (2009) para o gene IGF1; Peixoto et al. (2009) para o gene da Leptina; Figueiredo et al. (2008) para o gene da H-FABP (heart fatty acidbinding protein); Carmo et al. (2005) para o gene MYF5. Faria et al. (2006) para o gene GH; e Peixoto et al. (2006) para o gene da Leptina. Estes polimorfismos foram associados a importantes características de interesse econômico em suínos, como pode ser observado na Tabela 3.

Quanto ao mapeamento de QTL em suínos, podem ser citados os achados de Silva et al. (2008, 2009) no cromossomo quatro; Pires et al. (2008) no cromossomo seis; Paixão et al. (2008a,b) nos cromossomos 16, 17 e 18, alguns nunca antes mapeados; e Pires et al. (2005, 2006, 2007) no cromossomo 6. Estes QTLs revelaram importante influência sobre muitas características de interesse econômico, como listado na Tabela 3. Agora, o próximo passo será identificar que genes são direta ou indiretamente responsáveis pela ação desses QTLs, a fim de identificar que marcadores apresentariam maior potencial para utilização em programas de melhoramento.

Com enfoque na diversidade gênica, Souza et al. (2009) identificaram importante contribuição de raças Ibéricas como origem de raças suínas naturalizadas no Brasil por meio da análise mitocondrial do Citocromo b. Enquanto Sollero et al. (2009) construíram um painel de marcadores microssatélites com alta precisão (99,99\%) para identificação/exclusão de paternidade em raças naturalizadas do Brasil (Piau, Moura e Monteiro). 


\section{Considerações Finais}

A primeira década do Século XXI evidenciou a consolidação do melhoramento animal como importante campo de pesquisa no Brasil. Também se destaca o surgimento de novos estudos, principalmente, no âmbito da genética molecular aplicada ao melhoramento animal e da busca de novas características de interesse econômico, que provavelmente serão em breve inseridas em programas de avaliação genética de bovinos. Incrementos em modelagem estatística mostraram-se necessários para o aprimoramento das estimativas de componentes de variância e de parâmetros genéticos, talvez uma conseqüência da maior capacidade computacional obtida com o avanço dos aparatos de hardware ao longo da primeira década do século XXI. Pode se dizer também que as informações de marcadores moleculares serão de grande importância, num futuro próximo, em programas de melhoramento animal e o Brasil está bem amparado em grupos de pesquisa para este fim.

Porém, é importante ressaltar o reduzido número de trabalhos envolvendo algumas espécies de interesse zootécnico como, por exemplo, búfalos, caprinos, coelhos, equinos, ovinos e peixes, o que revela que ainda há muito a se fazer em termos de melhoramento animal no Brasil. Também é importante ressaltar que pouco se sabe sobre a difusão das informações geradas pelas pesquisas em melhoramento animal. Trabalhos de extensão rural para fins de divulgação das tecnologias geradas pelo melhoramento animal devem acompanhar os avanços gerados no âmbito das academias científicas, pois os maiores interessados, os produtores rurais, muitas vezes assimilam essas tecnologias de forma inadequada ou tardiamente. Portanto, para que o melhoramento animal tenha maior impacto na atividade pecuária brasileira é necessário que nas próximas décadas do século XXI haja uma continua consolidação dos grupos de pesquisa atuais; surgimento de grupos com interesses em espécies ainda pouco estudadas; e maior difusão tecnológica a campo.

\section{Referências}

ABATEPAUlO, A.R.R.; CAETANO, A.R.; MENDES JR., C.T. et al. Detection of SNPs in bovine immune-response genes that may mediate resistance to the cattle tick Rhipicephalus (Boophilus) microplus. Animal Genetics, v.39, p.328-329, 2008.

ALBUQUERQUE, L.G.; EL FARO, L. Comparações entre os valores genéticos para características de crescimento de bovinos da raça Nelore preditos com modelos de dimensão finita ou infinita. Revista Brasileira de Zootecnia, v.37, n.2, p.238-246, 2008.
AMBO, M.; MOURA, A.S.A.M.T.; LEDUR, M.C. et al. Quantitative trait loci for performance traits in a broiler layer cross. Animal Genetics, v.40, p.200-208, 2009.

ANDRADE, P.C.; GROSSI, D.A.; PAZ, C.C.P. et al. Association of an insulin-like growth factor 1 gene microsatellite with phenotypic variation and estimated breeding values of growth traits in Canchim cattle. Animal Genetics, v.39, p.480, 2008.

ARAÚJO, C.V.; TORRES, R.A.; COSTA, C.N. et al. Efeito da interação reprodutor $\mathrm{x}$ rebanho na acurácia da avaliação genética de reprodutores da raça holandesa no Brasil. Revista Brasileira de Zootecnia, v.30, p.1000-1006, 2001.

AZEVEDO JR., P.C.; SILVA, M.A.; FRIDRICH, A.B. et al. Comparação de metodologias para estimação de parâmetros genéticos em população de aves submetida à seleção. Arquivo Brasileiro de Medicina Veterinária e Zootecnia, v.54, n.5, p.518-524, 2002.

AZEVEDO, A.L.S.; NASCIMENTO, C.S.; STEINBERG, R.S. et al. Genetic polymorphism of the kappa-casein gene in Brazilian cattle. Genetics and Molecular Research, v.7, p.623-630, 2008.

AZEVÊDO, D.M.M.R.; MARTINS FILHO, R.; BOZZI, R. et al. Parâmetros genéticos e fenotípicos do desempenho reprodutivo de fêmeas Chianina. Revista Brasileira de Zootecnia, v.35, n.3, p.982-987, 2006a.

AZEVÊDO, D.M.M.R.; MARTINS FILHO, R.; LÔBO, R.N.B. Desempenho reprodutivo de vacas Nelore no Norte e Nordeste do Brasil. Revista Brasileira de Zootecnia, v.35, n.3, p.988996, 2006b.

AZEVÊDO, D.M.M.R.; MARTINS FILHO, R.; LÔBO, R.N.B. et al. Produtividade acumulada (PAC) das matrizes em rebanhos Nelore do Norte e Nordeste do Brasil. Revista Brasileira de Zootecnia, v.34, n.1, p.54-59, 2005.

BALDI, F.; ALENCAR, M.M.; FREITAS A.R. Correlações genéticas de características de tamanho corporal e condição corporal com características de eficiência produtiva de fêmeas da raça Canchim. Revista Brasileira de Zootecnia, v.37, n.3, p.420426, 2008b.

BALDI, F.; ALENCAR, M.M.; FREITAS, A.R. et al. Parâmetros genéticos para características de tamanho e condição corporal, eficiência reprodutiva e longevidade em fêmeas da raça Canchim. Revista Brasileira de Zootecnia, v.37, n.2, p.247-253, 2008a.

BAND, G.O.; GUIMARÃES, S.E.F.; LOPES, P.S. et al. Relationship between the Porcine Stress Syndrome gene and pork quality trait in F2 pigs resulting from divergent crosses. Genetics and Molecular Biology, v.28, n.1, p.88-91, 2005a.

BAND, G.O.; GUIMARÃES, S.E.F.; LOPES, P.S. et al. Relationship between the Porcine Stress Syndrome gene and carcass and performance trait in F2 pigs resulting from divergent crosses. Genetics and Molecular Biology, v.28, n.1, p.92-96, 2005b.

BARBOSA, L.; LOPES, P.S.; REGAZZI, A.J. et al. Estimação de parâmetros genéticos em suínos usando Amostrador de Gibbs. Revista Brasileira de Zootecnia, v.37, n.7, p.1200-1206, 2008.

BOLIGON, A.A.; ALBUQUERQUe, L.G.; RORATO, P.R.N. Associações genéticas entre pesos e características reprodutivas em rebanhos da raça Nelore. Revista Brasileira de Zootecnia, v.37, n.4, p.596-601, 2008.

BOLIGON, A.A.; ALBUQUERQUE, L.G. MERCADANTE, M E. Z. Study of relations among age at first calving, average weight gains and weights from weaning to maturity in Nellore cattle. Revista Brasileira de Zootecnia, v.39, n.4, p.746-751, 2010.

BOLIGON, A.A.; RORATO, P.R.N.; ALBUQUERQUE L.G. Correlações genéticas entre medidas de perímetro escrotal e características produtivas e reprodutivas de fêmeas da raça Nelore. Revista Brasileira de Zootecnia, v.36, n.3, p.565571, 2007.

BONGALHARDO, D.C.; DIONELLO, N.J.L.; LEDUR, M.C. et. al. Parâmetros genéticos para caracteres de sêmen de aves White 
Leghorn: 2. Correlações com caracteres de postura. Revista Brasileira de Zootecnia, v.29, n.2, p.392-396, 2000.

BONILHA, S.F.M.; PACKER, I.U.; FIGUEIREDO, L.A. et al. Efeitos da seleção para peso pós-desmame sobre características de carcaça e rendimento de cortes cárneos comerciais de bovinos. Revista Brasileira de Zootecnia, v.36, n.5, p.1275-1281, 2007.

BUENO, P.R.B.; RORATO P.R.N.; DÜRR J.W. et al. Valor Econômico para Componentes do Leite no Estado do Rio Grande do Sul. Revista Brasileira de Zootecnia, v.33, n.6, p.2256-2265, 2004.

CAMPOS, R.L.R.; AMBO, M.; ROSÁRIO, M.F. et al. Potential Association between Microsatellite markers on chicken chromosomes 6, 7 and 8 and body weight. International Journal of Poultry Science, v.8, p.696-699, 2009.

CAMPOS, R.L.R.; NONES, K.; LEDUR, M.C. et al. Quantitative trait loci associated with fatness in a broiler-layer cross. Animal Genetics, v.40, p.729-736, 2009.

CARDOSO, F.F.; ROSA, G.J.M.; TEMPELMAN, R.J. et al. Modelos hierárquicos bayesianos para estimação robusta e análise de dados censurados em melhoramento animal. Revista Brasileira de Zootecnia, v.38, p.72-80, 2009.

CARDOSO, V.L.; NOGUEIRA, J.R.; VERCESI FILHO, A.E. et al. Objetivos de seleção e valores econômicos de características de importância econômica para um sistema de produção de leite a pasto na região Sudeste. Revista Brasileira de Zootecnia, v.33, n.2, p.320-327, 2004.

CARMO, F.M.S.; GUIMARÃES, S.E.F.; LOPES, P.S. et al. Association of MYF5 gene allelic variants with production traits in pigs. Genetics and Molecular Biology, v.28, n.3, p.363-369, 2005.

CARNEIRO JR., J.M.; ASSIS, G.M.L.; EUCLYDES, R.F. et al. Estimação de componentes de variância utilizando-se inferência Bayesiana e freqüentista em dados simulados sob heterogeneidade de variâncias. Revista Brasileira de Zootecnia, v.36, n.5, p.1539-1548, 2007.

CARNEIRO JR., J.M.; ASSIS, G.M.L.; EUCLYDES, R.F. et al. Influência da informação a priori na avaliação genética animal utilizando dados simulados. Revista Brasileira de Zootecnia, v.34, p.1905-1913, 2005.

CARNEIRO JR., J.M.; EUCLYDES, R.F.; LOPES, P.S. et al. Avaliação de métodos de estimação de componentes de variância utilizando dados simulados. Revista Brasileira de Zootecnia, v.33, n.2, p.328-336, 2004.

CARNEIRO, A.P.S.; TORRES, R.A.; EUCLYDES, R.F. et al. Efeito da conexidade de dados sobre o valor fenotípico médio e a variância genética aditiva. Revista Brasileira de Zootecnia, v.30, n.2, p.336-341, 2001.

CARRIJO, S.M.; ALENCAR, M.M.; TORAL, F.L.B. et al. Association of PIT1 genotypes with growth traits in Canchim cattle. Scientia Agricola, v. 65, p.116-121, 2008.

CARVALHEIRO, E.; FRIES, L.A.; SCHENKEL, F.S. et al. Efeitos da heterogeneidade de variância residual entre grupos de contemporâneos na avaliação genética de bovinos de corte. Revista Brasileira de Zootecnia, v.31, n.4, p.1680-1688, 2002.

CASSOLI, C.S.S.; JORGE, E.C.; PATRICIO, M. et al. ESTs and putative line-specific (broiler and layer) SNPs identified in genes expressed in Gallus gallus pituitary and hypothalamus. Genetics and Molecular Biology, v.30, p.1077-1081, 2007.

CORREAA, M.B.B.; DIONELLO, N.J.L.; CARDOSO, F.F. Genetic evaluation of Devon Cattle using a reaction norms model. Revista Brasileira de Zootecnia, v.39, n.1, p.128-133, 2010.

COSTA, A.R.C.; LOPES, P.S.; TORRES, R.A. et al. Tendências genéticas em características de desempenho de suínos das raças Large White, Landrace e Duroc. Revista Brasileira de Zootecnia, v.30, p.348-352, 2001.
CUNHA, E.E.; EUCLYDES, R.F.; TORRES, R.A. et al. Impactos de se ignorarem os efeitos genéticos não-aditivos de dominância na avaliação genética animal. Revista Brasileira de Zootecnia, v.38, n.12, p.2354-2361, 2009.

DIAS, L.T.; ALBUQUERQUE, L.G.; TONHATI, H. et al. Estimação de parâmetros genéticos para peso do nascimento aos 550 dias de idade para animais da raça Tabapuã utilizando-se modelos de regressão aleatória. Revista Brasileira de Zootecnia, v.39, n.5, p.1037-1045, 2010.

DIAS, L.T.; EL FARO, L.; ALBUQUERQUE L.G. Estimativas de herdabilidade para perímetro escrotal de animais da raça Nelore. Revista Brasileira de Zootecnia, v.32, n.6, p.1878-1882, 2003.

EGITO, A.A.; PAIVA, S.R.; ALBUQUERQUE, M.S.M. et al. Microsatellite based genetic diversity and relationships among ten creole and commercial cattle breeds raised in Brazil. BMC Genetics, v.8, p.1-14, 2007.

FARIA, D.A.; GUIMARÃES, S.E.F.; LOPES, P.S. et al. Association between G316A growth hormone polymorphism and economic traits in pigs. Genetics and Molecular Biology, v.29, p.634640, 2006.

FARIA, D.A.; PEIXOTO, J.O.; LOPES, P. et al. Association between insulin-like growth factor I microsatellite polymorphisms and important economic traits in pigs. Revista Brasileira de Zootecnia, v.38, p.265-270, 2009.

FERRAZ, J.B.S.; PINTO, L.F.B.; MEIRELLES, F.V. et al. Association of single nucleotide polymorphisms with carcass traits in Nellore cattle. Genetics and Molecular Research, v.8, p.1360-1366, 2009.

FIGUEIREDO, F.C.; LOPES, P.S.; PINTO, A.P.G. et al. Association of the heart fatty acid-binding protein gene with quality of carcass and meat traits in pigs. Arquivo Brasileiro de Medicina Veterinária e Zootecnia, v.60, p.408, 2008.

FRAGA, A.B.; ALENCAR, M.M.; FIGUEIREDO, L.A. Análise de Fatores Genéticos e Ambientais que Afetam a Infestação de Fêmeas Bovinas da Raça Caracu por Carrapatos (Boophilus microplus). Revista Brasileira de Zootecnia, v.32, n.6, p.1578-1586, 2003.

FREITAS, A.R.; PRESOTTI, C.V.; TORAL, F.L.B. Alternativas de Análises em Dados de Medidas Repetidas de Bovinos de Corte. Revista Brasileira de Zootecnia, v.34, n.6, p.2233-2244, 2005.

GASPARIN, G.; MIYATA, M.; COUTINHO, L.L. et al. Mapping of quantitative trait loci controlling tick [Riphicephalus (Boophilus) microplus] resistance on bovine chromosomes 5, 7 and 14. Animal Genetics, v.38, p.453-459, 2007.

GASPARIN, G.; MIYATA, M.; COUTINHO, L.L. et al. Quantitative trait locus affecting birth weight on bovine chromosome 5 in a F2 Gyr x Holstein population. Genetics and Molecular Biology, v.28, n.4, p.670-676, 2005.

GAYA, L.G.; MOURÃO, G.B.; SILVA J.A. II V. et al. Estimativas de herdabilidade para os escores visuais do coração e do fígado em linhagem macho de frangos. Brazilian Journal of Veterinary Research and Animal Science, v.43, n.6, p.734-738, 2006.

GIANNOTTI, J.D.G.; PACKER, I.U.; MERCADANTE M.E.Z. Meta-Análise para estimativas de herdabilidade para características de crescimento em bovinos de corte. Revista Brasileira de Zootecnia, v.34, n.4, p.1173-1180, 2005.

GIBBS, R.A.; TAYLOR, J.F.; VAN TASSELL, C.P. et al. Genomewide survey of SNP variation uncovers the genetic structure of cattle breeds. Science, v.324, p.528-531, 2009.

JORGE JR., J.; CARDOSO, V.L.; ALBUQUERQUE L.G. Objetivos de seleção e valores econômicos em sistemas de produção de gado de corte no Brasil. Revista Brasileira de Zootecnia, v.36, p.1549-1558, 2007.

JORGE, E.C.; FIGUEIRA, A.; LEDUR, M.C. Contributions and perspectives of chicken genomics in Brazil: from biological model to export commodity. World's Poultry Science Journal, v.63, p.597-610, 2007. 
KOURY FILHO, W.; ALBUQUERQUE, L.G.; FORNI, S. et al. Estimativas de parâmetros genéticos para os escores visuais e suas associações com peso corporal em bovinos de corte. Revista Brasileira de Zootecnia, v.39, n.5, p.1015-1022, 2010.

LACORTE, G.A.; MACHADO, M.A.; MARTINEZ, M.L. et al. DGAT1 K232A polymorphism in Brazilian cattle breeds. Genetics and Molecular Research, v.5, n.3, p.475-482, 2006.

LÔBO, A.M.B.O.; LÔBO, R.N.B.; PAIVA, S.R. Aromatase gene and its effects on growth, reproductive and maternal ability traits in a multibreed sheep population from Brazil. Genetics and Molecular Biology, v.32, 484-490, 2009.

LÔBO, R.N.B.; MARTINS FILHO, R. Avaliação de métodos de padronização dos pesos corporais às idades de 205, 365 e 550 dias. Revista Brasileira de Zootecnia, v.31, p.1695-1706, 2002

LOURENÇO, F.F.; DIONELLO, N.J.L.; MEDEIROS, G.C.R. et al. Estudos genéticos sobre a leitegada em suínos da raça Landrace criados no Rio Grande do Sul. Revista Brasileira de Zootecnia, v.37, n.9, p.1601-1606, 2008.

MACHADO, M.A.; AZEVEDO, A.L.S.; TEODORO, R.L. et al. Genome wide scan for quantitative trait loci affecting tick resistance in cattle (Bos taurus x Bos indicus). BMC Genomics, v.11, n.280, p.1-11, 2010.

MACHADO, M.A.; NASCIMENTO, C.S.; MARTINEZ, M.L. et al. Associação do loco BoLA-DRB3.2 com produção de leite em bovinos da raça Gir. Arquivo Brasileiro de Medicina Veterinária e Zootecnia, v.57, n.3, p.380-389, 2005.

MACHADO, M.A.; SCHUSTER, I.; MARTINEZ, M.L. et al. Genetic diversity of four cattle breeds using microsatellite markers. Revista Brasileira de Zootecnia, v.32, n.1, p.9398, 2003.

MAfFEI, W.E. Reatividade animal. Revista Brasileira de Zootecnia, v.38, p.81-92, 2009.

MAIA, A.S.C.; SILVA, R.G.; BERTIPAGLIA, E.C.A. Características do pelame de vacas holandesas em ambiente tropical: um estudo genético e adaptativo. Revista Brasileira de Zootecnia, v.32, n.4, p.843-853, 2003.

MARSON, E.P.; FERRAZ, J.B.S.; MEIRELLES, F.V. et al. Effects of polymorphisms of LHR and FSHR genes on sexual precocity in a Bos taurus x Bos indicus beef composite population. Genetics and Molecular Research, v.7, p.243-251, 2008.

MARTINEZ, M.L.; MACHADO, M.A.; NASCIMENTO, C.S. et al. Association of BoLA-DRB3.2 alleles with tick (Boophilus microplus) resistance in bovine. Genetics and Molecular Research, v.5, n.3, p.513-524, 2006.

MARTINS, G.A.; MADALENA, F.E.; BRUSCHI, J.H. et al. Objetivos econômicos de seleção de bovinos de leite para fazenda demonstrativa na Zona da Mata de Minas Gerais. Revista Brasileira de Zootecnia, v.32, n.2, p.304-314, 2003.

MATTAR, M.; OLIVEIRA, J.A.; MEIRELLES, S.L. et al. Efeitos genéticos e ambientais sobre o perímetro escrotal de animais da raça Caracu. Revista Brasileira de Zootecnia, v.36, n.6, p.2010-2015, 2007.

MÉO, S.C.; FERREIRA, C.R.; CHIARATTI, M.R. et al. Characterization of mitochondrial genotypes in the foundation herd of the Canchim beef cattle breed. Genetics and Molecular Research, v.8, p.261-267, 2009.

MERCADANTE, M.E.Z.; PACKER, I.U.; RAZOOK, A.G. et al. Quadrados mínimos e modelo misto no acesso à estimativa da resposta direta à seleção em rebanhos experimentais de bovinos Nelore. Revista Brasileira de Zootecnia, v.32, n.5, p.11231130, 2003

MERCADANTE, M.E.Z.; RAZOOK, A.G.; CYRILLO, J.N.S.G. et al. Efeito da seleção para crescimento na permanência de vacas Nelore no rebanho até cinco anos de idade. Revista Brasileira de Zootecnia, v.33, n.2, p.344-349, 2004.
MERCADANTE, M.E.Z.; SILVA, S.L.; BUENO, M.S. et al. Repetibilidade da mensuração de imagens das características de carcaça obtidas por ultrassonografia em fêmeas Nelore. Revista Brasileira de Zootecnia, v.39, n.4, p.752-757, 2010.

MILAZZOTTO, M.; RAHAL, P.; NICHI, M. et al. New molecular variants of hypothalamus pituitary gonad axis genes and their association with early puberty phenotype in Bos taurus indicus (Nellore). Livestock Science, v.114, p.274-279, 2008.

MIYATA, M.; GASPARIN, G.; COUTINHO, L.L. et al. Quantitative trait loci (QTL) mapping for growth traits on bovine chromosome 14. Genetics and Molecular Biology, v.30, p.364-369, 2007.

NASCIMENTO, C.S.; MACHADO, M.A.; MARTINEZ, M.L. et al. Association of the bovine major histocompatibility complex (BoLA) BoLA-DRB3 gene with fat and protein production and somatic cell score in Brazilian Gyr dairy cattle (Bos indicus). Genetics and Molecular Biology, v.29, n.4, p.641-647, 2006.

NONES, K.; LEDUR, M.C.; RUY, D.C. et al. Mapping QTLs on chicken chromosome 1 for performance and carcass traits in a broiler x layer cross. Animal Genetics, v.37, p.95-100, 2006.

OLIVEIRA, R.R.; EGITO, A.A.; RIBEIRO, M.N. et al. Genetic characterization of the Moxotó goat breed using RAPD markers. Pesquisa Agropecuária Brasileira, v.40, n.3, p.233-239, 2005.

PAIVA, S.R.; FARIA, D.A.; McMANUS, C.M. et al. Origin of the main locally adapted sheep breeds of Brazil: a RFLP-PCR molecular analysis. Archivos de Zootecnia, v.54, p.395-399, 2005 b.

PAIVA, S.R.; SILVÉRIO, V.C.; EGITO, A.A. et al. Genetic variability of the main Brazilian hair sheep breeds using RAPDPCR markers and conservation implications. Pesquisa Agropecuária Brasileira, v.40, n.9, p.887-893, 2005a.

PAIXÃO, D.M.; GUIMARÃES, S.E.F.; SILVA FILHO, M.I. et al. Detecção de locos de características quantitativas nos cromossomos 16, 17 e 18 de suínos. Revista Brasileira de Zootecnia, v.37, p.1781-1787, 2008a.

PAIXÃO, D.M.; SILVA FILHO, M.I.; PEREIRA, M.S. et al. Quantitative trait loci for carcass, internal organ and meat quality traits on porcine chromosomes 16, 17 and 18. Genetics and Molecular Biology, v.31, p.898-901, $2008 \mathrm{~b}$.

PEIXOTO, J.O.; FARIA, D.A.; SILVA, P.V. et al. Association between leptin gene single nucleotide polymorphisms and carcass traits in pigs. Revista Brasileira de Zootecnia, v.38, p.271276, 2009.

PEIXOTO, J.O.; GUIMARÃES, S.E.F.; LOPES, P.S. et al. Associations of leptin gene polymorphisms with production traits in pigs. Journal of Animal Breeding and Genetics, v.123, p.378383, 2006.

PELICIONI, L.C.; QUEIROZ, S.A. Efeito da linhagem citoplasmática sobre a produção de leite em bovinos da raça Caracu. Revista Brasileira de Zootecnia, v. 30, p.109-114, 2001.

PEREIRA, A.P.; ALENCAR, M.M.; OLIVEIRA, H.N. et al. Association of GH and IGF-1 polymorphisms with growth traits in a synthetic beef cattle breed. Genetics and Molecular Biology, v.28, n.2, p.230-236, 2005.

PEREIRA, V.M.C.; ALENCAR, M.M.; BARBOSA, R.T. Estimativas de parâmetros genéticos e de ganhos direto e indireto à seleção para características reprodutivas e de crescimento em um rebanho da raça Canchim. Revista Brasileira de Zootecnia, v.36, n.4, p.1029-1036, 2007.

PEROTTO, D.; ABRAHÃO, J.J.S.; MOLETTA, J.L. et al. Physical composition, primary cuts and meat cuts of carcasses from Zebu and Bos taurus $\times$ Bos indicus crossbred cattle. Revista Brasileira de Zootecnia, v.38, n.9, p.1712-1718, 2009.

PETROLI, C.D.; PAIVA, S.R.; CORRÊA, M.P.C. et al. Genetic monitoring of a Santa Ines herd using microsatellite markers near or linked to the sheep MHC1. Revista Brasileira de Zootecnia, v.38, n.4, p.670-675, 2009. 
PIRES, A.V.; LOPES, P.S.; GUIMARÃES, C.T. et al. Mapping quantitative trait loci for performance traits on pig chromosome 6 (SSC6). Archivos Latinoamericanos de Producción Animal, v.15, p. 25-32, 2007.

PIRES, A.V.; LOPES, P.S.; GUIMARÃES, S.E.F. et al. Quantitative trait loci mapping for meat quality traits in swine chromosome 6. Arquivo Brasileiro de Medicina Veterinária e Zootecnia, v.57, n.5, p.608-615, 2005.

PIRES, A.V.; LOPES, P.S.; GUIMARÃES, S.E.F. Mapeamento de locos de características quantitativas no cromossomo 6 , associados às características de carcaça e de órgãos internos de suínos. Revista Brasileira de Zootecnia, v.35, n.4, p.16601668, 2006

PIRES, A.V.; LOPES, P.S.; GUIMARÃES, S.E.F. et al. Mapeamento de locos de características quantitativas associados à composição de carcaça, no cromossomo seis de suíno. Arquivo Brasileiro de Medicina Veterinária e Zootecnia, v.60, p.725-732, 2008.

PITA, F.V.C.; ALBUQUERQUE, L.G. Resposta à seleção para características de desempenho em um rebanho de seleção de suínos. Revista Brasileira de Zootecnia, v.30, p.2009-2016, 2001.

QUEIROZ, S.A.; FIGUEIREDO, G.; SILVA, J.A. II V. et al. Estimativa de parâmetros genéticos da habilidade de permanência aos 48, 60 e 72 meses de idade em vacas da raça Caracu. Revista Brasileira de Zootecnia, v.36, n.5, p.1316-1323, 2007.

RIBEIRO, A.C.; MCALLISTER, A.J.; QUEIROZ, S.A. Profitability measures of dairy cows. Revista Brasileira de Zootecnia, v.37, p.1607-1616, 2008.

SENO, L.O.; CARDOSO, V.L.; TONHATI, H. Valores econômicos para as características de produção de leite de búfalas no estado de São Paulo. Revista Brasileira de Zootecnia, v.36, n.6, p.2016-2022, 2007.

SHIOTSUKI, L.; SILVA, J.A. II V.; ALBUQUERQUE, L.G. Associação genética da prenhez aos 16 meses com o peso a desmama e o ganho de peso em animais da raça Nelore. Revista Brasileira de Zootecnia, v.38, n.7, p.1211-1217, 2009

SILVA, J.A. II V.; DIAS, L.T.; ALBUQUERQUE, L.G. Estudo genético da precocidade sexual de novilhas em um rebanho Nelore. Revista Brasileira de Zootecnia, v.34, n.5, p.1568$1572,2005$.

SILVA, J.A. II V.; VAN MELIS, M.H.; ELER, J.P. et al. Estimação de parâmetros genéticos para probabilidade de prenhez aos 14 meses e altura na garupa em bovinos da raça Nelore. Revista Brasileira de Zootecnia, v.32, n.5, p.1141-1146, 2003.

SILVA, K.M.; PAIXÃO, D.M.; SILVA, P.V. et al. Mapping of quantitative trait loci and confirmation of the FAT1 region on chromosome 4 in an F2 population of pigs. Genetics and Molecular Biology, v.31, p.475-480, 2008.

SILVA, K.M.; GUIMARÃES, S.E.F.; LOPES, P.S. et al. Mapeamento de locos de características quantitativas para desempenho no cromossomo 4 de suínos. Revista Brasileira de Zootecnia, v.38, p.474-479, 2009.

SILVA, M.V.G.B.; MARTINEZ, M.L.; MACHADO, M.A. et al. Genes do eixo somatotrófico e características de crescimento numa população F2 de bovinos. Pesquisa Agropecuária Brasileira, v.41, p. 981-986, 2006.

SILVEIRA, L.G.G.; FURLAN, L.R.; CURI, R.A. et al. Growth hormone 1 gene (GH1) polymorphisms as possible markers of the production potential of beef cattle using the Brazilian Canchim breed as a model. Genetics and Molecular Biology, v.31, p.874-879, 2008.

SOLLERO, B.P.; PAIVA, S.R.; FARIA, D.A. et al. Genetic diversity of Brazilian pig breeds evidenced by microsatellite markers. Livestock Science, v.123, p.8-15, 2009.

SOUSA JR., S.C.; OLIVEIRA, S.M.P.; ALBUQUERQUE, L.G. et al. Estimação de funções de covariância para características de crescimento da raça Tabapuã utilizando modelos de regressão aleatória. Revista Brasileira de Zootecnia, v.39, n.5, p.1037-1045, 2010.

SOUZA, C.A.; PAIVA, S.R.; PEREIRA, R.W. et al. Iberian origin of Brazilian local pig breeds based on cytochrome b (MTCYB) Sequence. Animal Genetics, v.40, p.759-762, 2009.

TAMBASCO, D.D.; TAMBASCOSTUDART, M.D.; PEREIRA, A.P. et al. Candidate genes for growth traits in beef cattle crosses Bos taurus x Bos indicus. Journal of Animal Breeding and Genetics, v.120, n.1, p.51-56, 2002.

THOLON, P.; QUEIROZ, S.A. Modelos matemáticos utilizados para descrever curvas de crescimento em aves aplicados ao melhoramento genético animal. Ciência Rural, v.39, n.7, p.2261-2269, 2009.

TORAL, F.L.B.; ALENCAR, M.M.; FREITAS, A.R. Abordagens freqüentista e bayesiana para avaliação genética de bovinos da raça Canchim para características de crescimento. Revista Brasileira de Zootecnia, v.36, n.1, p.43-53, 2007.

TORAL, F.L.B.; ALENCAR, M.M.; FREITAS A.R. Arranjos para efeitos fixos e estruturas de (co)variâncias residuais para análises de medidas repetidas do peso de bovinos da raça Canchim. Revista Brasileira de Zootecnia, v.34, p.22332244, 2005.

TORAL, F.L.B.; ALENCAR, M.M.; FREITAS, A.R. Estruturas de variância residual para estimação de funções de covariância para o peso de bovinos da raça Canchim. Revista Brasileira de Zootecnia, v.38, n.11, p.2152-2160, 2009.

TORRES FILHO, R.A.; TORRES, R.A.; LOPES, P.S. et al. Estimativas de parâmetros genéticos para características reprodutivas de suínos. Arquivo Brasileiro de Medicina Veterinária e Zootecnia, v.57, n.5, p.684-689, 2005.

UNANIAN, M.M.; BARRETO, C.C.; FREITAS, A.R. et al. Associação do polimorfismo do gene do hormônio de crescimento com a característica peso em bovinos da raça Nelore. Revista Brasileira de Zootecnia, v.29, p.13801386, 2000.

VAN MELIS, M.H.; ELER, J.P.; SILVA, J.A. II V. et al. Estimação de parâmetros genéticos em bovinos de corte utilizando os métodos de Máxima Verossimilhança Restrita e R1. Revista Brasileira de Zootecnia, v.32, n.6, p.1624-1632, 2003.

VAYEGO, S.A.; DIONELLO, N.J.L.; FIGUEIREDO, E.A.P. Estimativas de parâmetros e tendências genéticas para algumas características de importância econômica em linhagem paterna de frangos de corte sob seleção. Revista Brasileira de Zootecnia, v.37, n.7, p.1230-1235, 2008.

VAZ, F.N.; RESTLE, J.; VAZ, R.Z. et al. Efeitos de raça e heterose na composição física da carcaça e na qualidade da carne de novilhos da primeira geração de cruzamento entre Charolês e Nelore. Revista Brasileira de Zootecnia, v.31, n.1, p.376-386, 2002. 